\title{
On the effect of stiffness/softness and morphology of interphase phase on the effective elastic properties of three-phase composite material
}

\author{
Kamel Fedaoui, Lazhar Baroura, Karim Arar \\ University of Constantine 1, Constantine, Algeria \\ Kamel.fedaoui@umc.edu.d₹, https://orcid.org/0000-0003-0885-6914 \\ barouralaz@yahoo.fr,bttps://orcid.org/0000-0002-6747-5049 \\ arar_karim@yaboo.fr
}

\author{
Hichem Amrani \\ University of Batna 2, Batna, Algeria \\ amranibichem78@hotmail.fr
}

\author{
Mohamed said Boutaani \\ University of Bejaia, Bejaia, Algeria \\ poutasfr@yahoo.fr, https:/ / orcid.org/0000-0003-2003-2432
}

ABSTRACT. In the present study, Composite material consisting of an elastic homogeneous isotropic matrix in which are embedded coated elastic isotropic inclusions, widely used in many applications is investigated by a homogenization approach coupled to the finite element method. A finite element model is proposed to predict the Young's and shear modulus of the three-phase composite containing spherical inclusions surrounded by a spherical or ellipsoid interphase layer. Three cases of particle volume fractions and interphase were considered with the addition of two interphase morphologies. Young's modulus of the interphase region was varied from soft to hard than the matrix properties. We note the interphase morphology and properties play an important role in the elastic properties of composite with increasing the volume fraction of inclusions and interphase. The results were compared to the first-order bounds Voigt and Reuss, and the mean-field homogenization techniques. A sensitive study of the effect of mesh density on the results of the von Mises stresses and elastic properties has been made.

KEYWORDS. Three-component composites; Interphase; Representative volume element; Unit cell; Effective elastic properties.

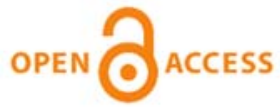

Citation: Fedaoui., K., Baroura, L., Arar, K., Amrani, H., Boutaani, M.S., On the effect of stiffness/softness and morphology of interphase phase on the effective elastic properties of three-phase composite material, Frattura ed Integrità Strutturale, 55 (2021) 3649.

Received: 27.08 .2020

Accepted: 07.10.2020

Published: 01.01.2021

Copyright: (C) 2021 This is an open access article under the terms of the CC-BY 4.0, which permits unrestricted use, distribution, and reproduction in any medium, provided the original author and source are credited. 


\section{INTRODUCTION}

$\mathrm{F}$ or the industrial need in material characteristics, properties and strength of these materials in their mission can be ameliorated by mastering the design of components properties (improve building energy efficiency [1-6]. Various techniques are used to give to the composite a great performance by choice of the inclusions shapes, the inclusions properties or the numbers of inclusions [7-10]. Another method is by the creation of interphase between the matrix and other phases. These interphases are formed by a desired or natural chemical reaction between the matrix and particles or the use of protective coatings during manufacturing. The incorporation of an interphase between the constituents of composite affects it elastic properties. Although small in thickness, interphases affect the overall mechanical properties of the particle reinforced composites. The effective elastic properties of the composite are related to the constituent's elastic properties and their volume fraction. Numerous experimental, analytical or computational techniques like finite element method were adopted to study the effects of various parameters like the morphology, properties of inclusions on the composite material [11-18].

This interphases phenomena influence was the object of many works and various micromechanical techniques were proposed in the literature. A simple example of the material where interphase is important is the concrete with the creation of the interfacial transition zone (ITZ) which exists in cement paste near sand particles and aggregates. Concrete must be considered as a three-phase composite: (1) cement paste, (2) ITZ, and (3) aggregates, see [6, 19]. For the Ductile Cast Irons, fatigue crack propagation is strongly influenced by the matrix and by the presence of graphite inclusions. In the work of [20], the role played by the graphite inclusions and interphase during the fatigue crack propagation was investigated by means of Light Optical Microscope observations of transversal sections of metallographically prepared fatigue fracture surfaces.

Because of their potential, core/shell composites have been the subject of numerous experimental and theoretical investigations as the use of core/shell nanoparticles in different fields such as building materials for energy efficiency, as well as in biomedical and biological fields, for the treatment of tumors [21, 22] and medical imaging. Composites with a metal matrix reinforced with particles find their uses for their strength / rigidity ratio in a wide range of products such as the aerospace, weapons, automotive industries [23]. CNT (carbon nanotube) is characterized by a surrounding region which has a significant influence on the mechanical properties of the composite [24]. For this, the properties of the latter must be taken into account in the modeling of these materials. Recent research has explored the possibility of having complex composites with controllable particle sizes and morphologies. The properties thus obtained allow the use of these composites in solar energy, photothermal and electronic fields, [25].

For the micromechanical model, Voigt and Reuss proposed a general expression for all the composites with an upper and lower bounds for the elastic modulus taking into account the volume fractions of phases and their elastic properties [26, 27]. The beginner to investigate the effects of a thin interphase on local fields and the resulting effective properties of composite made of coated ellipsoidal inclusion were Walpole and Cherkaoui et al. [28, 11], by the self-consistent estimate developed a general expression for the prediction of effective parameters of a particle-filled composite with thin interphase while Aboutajeddine and Neale [29] proposed a general form of elastic properties taken into account the Mori-Tanaka method. In other papers, $[30,31]$, the thermo-elastic behavior of matrix reinforced with long continuous coated fiber was studied. Herve and Zaoui in $[32,33]$ generalized the model used for the representation of the three-phase model to a model composed of $n$-layered spherical inclusion. In [34], Lipinski et al. proposed the use of the model proposed by Hervé and Zaoui's work for the $n$-layered spherical inclusion morphology to study the $n$-layered ellipsoidal inclusion configurations. In Berger et al. [35], the effective thermo-mechanical properties of three-phase composites (one of the three-phase is considered an interphase) for different configurations were estimated using a unit cell.

Alexander et al. studied the prediction of effective thermal conductivity of spherical random distributed core-shell particles distributed in a continuous matrix [36]. In Cabeza et al.- [6] and Benjamin, [12], the effective mechanical properties phase change materials PCM used in building material composed of three-phase were predicted using finite element technique and elastic deformation. Benjamin in $[12,13]$ examined the effects of microencapsulated phase change materials (PCMs)on the thermal deformation behavior of cement-based composites. In Böhm, [37] material reinforced by coated spheres is investigated by some analytical techniques and the use of periodic homogenization. In all the preceding work, composite material is taken like a periodic array of repetitive unit cells.

In this paper, we present a computational micromechanical investigation of the effect of interphase on the mechanical properties and strength of materials. We study a few material configurations (properties, morphology, and volume fraction) using the finite element method to explore how the interface morphology and properties affect the material behavior. The 
objective of the current paper is the determination of the effective elastic properties and the study of the effects of interphase on these properties.

\section{ANALYSIS}

\section{Unit cell and phases properties}

$\mathrm{I}$ n our case, composite material is taken like a periodic array of repetitive unit cells, constructed with uniform distribution of the same morphology for the reinforcing phase. The micro-mechanical approach chooses this unit cell as the representative volume element (RVE) for the composites. The length of the unit cell is set to $0.1 \mathrm{~mm}$.

The proposed RVE containing the interphase phase, surrounded by the matrix and the spherical inclusion located at the center is schematically represented in Fig. 1, see Amraei, [38]. The coated inclusions are formed by spherical inclusions surrounded by the interphase. For the morphology of the interphase, the spherical and ellipsoid form is adopted.
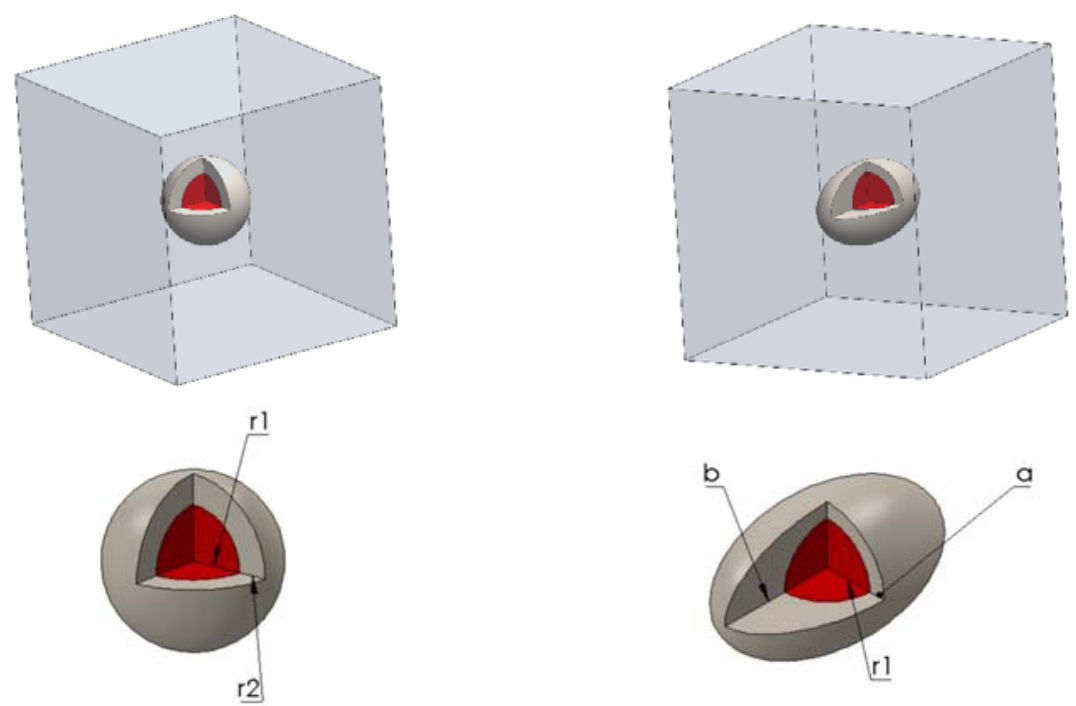

Figure 1: Schematics of unit cells with morphology of interphase, spherical and ellipsoids used for numerical simulations

The volume of a hollow sphere (interphase) with radius of the overall sphere $r_{1}$ and the radius of the hollowed region $r_{2}$ can be determined as:

$$
V_{\text {sphe- }- \text { bollow }}=\frac{4}{3} \pi *\left(r_{2}^{3}-r_{1}^{3}\right)
$$

For the ellipsoid interphase we have:

$$
V_{\text {ellip-bollow }}=\frac{4}{3} \pi *\left(a^{2} * b\right)-\frac{4}{3} \pi^{*} r_{1}^{3}
$$

Tab. 1 shows the cases of RVE in this study.

In this study, $V_{i}, P_{i}$ and $r_{i}$ represents respectively the volume of inclusions, the volume fraction and the radius of the $\mathrm{i}^{\text {th }}$ phase. $\mathrm{P}$ is the volume fraction of the matrix phase. Three cases of volume fraction of the interface are considered in this work. Firstly the volume of interphase is equal to the volume of inclusion, secondly is half and finally the volume of interphase is one on three of inclusion volume. Three different volume fractions of matrix are considered $P=95 \%, 90 \%$ and $70 \%$.

In this paper, $0 \leq P_{i} \leq 1$.

$P_{i}=1$ corresponds to $100 \%$ of the $i^{\text {th }}$ phase. 
$P$ is the surface fraction of the matrix phase, so $P+\sum_{i=1}^{2} P_{i}=1$.

\begin{tabular}{|c|c|c|c|c|}
\hline \multirow[b]{2}{*}{ Volume fraction } & \multirow[b]{2}{*}{ Shape } & \multicolumn{3}{|c|}{ Cases } \\
\hline & & $V_{\text {Interphase }}=V_{\text {inclusion }}$ & $V_{\text {Interphase }}=V_{\text {inclusion }} / 2$ & $V_{\text {Interphase }}=V_{\text {inclusion }} / 3$ \\
\hline$P_{1}=P_{2}=2.5 \%$ & $\begin{array}{l}\text { sphere } \\
\text { interphase } \\
\text { ellipsoid } \\
\text { interphase }\end{array}$ & $\begin{aligned} \mathrm{r}_{1} & =0.018 \mathrm{~mm} \\
\mathrm{r}_{2} & =0.023 \mathrm{~mm} \\
\mathrm{r}_{1} & =0.018 \mathrm{~mm} \\
\mathrm{a} & =0.019 \mathrm{~mm} \\
\mathrm{~b} & =0.032 \mathrm{~mm}\end{aligned}$ & $\begin{aligned} \mathrm{r}_{1} & =0.018 \mathrm{~mm} \\
\mathrm{r}_{2} & =0.021 \mathrm{~mm} \\
\mathrm{r}_{1} & =0.018 \mathrm{~mm} \\
\mathrm{a} & =0.019 \mathrm{~mm} \\
\mathrm{~b} & =0.024 \mathrm{~mm}\end{aligned}$ & $\begin{array}{c}\mathrm{r}_{1}=0.018 \mathrm{~mm} \\
\mathrm{r}_{2}=0.02 \mathrm{~mm} \\
\mathrm{r}_{1}=0.018 \mathrm{~mm} \\
\mathrm{a}=0.019 \mathrm{~mm} \\
\mathrm{~b}=0.021 \mathrm{~mm}\end{array}$ \\
\hline$P_{1}=P_{2}=5 \%$ & $\begin{array}{c}\text { sphere } \\
\text { interphase } \\
\text { ellipsoid } \\
\text { interphase }\end{array}$ & $\begin{aligned} \mathrm{r}_{1} & =0.023 \mathrm{~mm} \\
\mathrm{r}_{2} & =0.029 \mathrm{~mm} \\
\mathrm{r}_{1} & =0.023 \mathrm{~mm} \\
\mathrm{a} & =0.024 \mathrm{~mm} \\
\mathrm{~b} & =0.04 \mathrm{~mm}\end{aligned}$ & $\begin{aligned} \mathrm{r}_{1} & =0.023 \mathrm{~mm} \\
\mathrm{r}_{2} & =0.026 \mathrm{~mm} \\
\mathrm{r}_{1} & =0.023 \mathrm{~mm} \\
\mathrm{a} & =0.024 \mathrm{~mm} \\
\mathrm{~b} & =0.03 \mathrm{~mm}\end{aligned}$ & $\begin{array}{l}\mathrm{r}_{1}=0.023 \mathrm{~mm} \\
\mathrm{r}_{2}=0.025 \mathrm{~mm} \\
\mathrm{r}_{1}=0.023 \mathrm{~mm} \\
\mathrm{a}=0.024 \mathrm{~mm} \\
\mathrm{~b}=0.036 \mathrm{~mm}\end{array}$ \\
\hline$P_{1}=P_{2}=15 \%$ & $\begin{array}{c}\text { sphere } \\
\text { interphase } \\
\text { ellipsoid } \\
\text { interphase }\end{array}$ & $\begin{array}{l}\mathrm{r}_{1}=0.033 \mathrm{~mm} \\
\mathrm{r}_{2}=0.042 \mathrm{~mm} \\
\mathrm{r}_{1}=0.033 \mathrm{~mm} \\
\mathrm{a}=0.035 \mathrm{~mm} \\
\mathrm{~b}=0.058 \mathrm{~mm}\end{array}$ & $\begin{array}{l}\mathrm{r}_{1}=0.033 \mathrm{~mm} \\
\mathrm{r}_{2}=0.038 \mathrm{~mm} \\
\mathrm{r}_{1}=0.033 \mathrm{~mm} \\
\mathrm{a}=0.035 \mathrm{~mm} \\
\mathrm{~b}=0.043 \mathrm{~mm}\end{array}$ & $\begin{array}{l}\mathrm{r}_{1}=0.033 \mathrm{~mm} \\
\mathrm{r}_{2}=0.036 \mathrm{~mm} \\
\mathrm{r}_{1}=0.033 \mathrm{~mm} \\
\mathrm{a}=0.035 \mathrm{~mm} \\
\mathrm{~b}=0.038 \mathrm{~mm}\end{array}$ \\
\hline
\end{tabular}

Table 1: Cases of materials.

\begin{tabular}{ccc}
\hline Phases & Elastic properties & \\
& $E[\mathrm{MPa}]$ & $v$ \\
Matrix & 1 & 0.3 \\
Inclusion & 5 & 0.2 \\
Interphase & 0.10 .20 .50 .8135810 & 0.3 \\
\hline
\end{tabular}

Table 2: Elastic properties of considered material.

All the components are considered isotropic, this means that their combination in the unit cell generates a composite with isotropic behavior. We note that interphase is located between the matrix and inclusion, its elastic properties are affected by the elastic properties of the two phases. The Young's modulus $E$ and the Poisson's ratio $v$ of all phases are presented in Tab. 2.

\section{Governing equations}

Linear elastic constitutive relationships for an isotropic material are given by [39].

$$
\sigma_{i j}=C_{i j k l} \varepsilon_{k l}
$$

where $\{i, j, k, l\} \in\{1,2,3\}$

For homogeneous and isotropic materials the tensor $C$ is given by:

$$
C_{i j k l}=\lambda \delta_{i j} \delta_{k l}+\mu\left(\delta_{k l} \delta_{j l}+\delta_{i l} \delta_{j k}\right)
$$

with $\lambda$ and $\mu$ are the Lamé parameters and $\delta_{\alpha \beta}$ denote a Kronecker delta. The elastic moduli are expressed by:

$$
\lambda=\frac{E v}{(1+v)(1-2 v)}=K-\frac{2}{3} G, \mu=\frac{E}{2(1+v)}=G
$$


This constitutive law can be determined based on the detailed fields in the selected unit cell through an "averaging" procedure. First, the differential equilibrium equation in any component is expressed as (Hjelmstad, 2005):

$$
\sigma_{i j, j}=0
$$

Second, the strain-displacement relation in any component is given by:

$$
\varepsilon=\frac{1}{2}\left(\mu_{i, j}+\mu_{j, i}\right)
$$

where $u=[u, v, w]^{T}$ is the displacement vector. Finally, the constitutive law for each constituent is given by:

$$
\sigma=\mathrm{C}_{\mathrm{I}}: \varepsilon
$$

where $I=\{m$, inc, inter $\}$

Combining Eqns. (16) - (18), results in governing equations expressed solely in terms of the displacement field. These equations are referred to as Navier's equations, which, for the present case, are given by:

$$
\left(\lambda_{I}+\mu_{I}\right) \nabla\left(\nabla \cdot u_{I}\right)+\mu_{I} \nabla^{2} u_{I}=0
$$

where $\lambda_{I}$ and $\mu_{I}$ are the Lamé parameters for each component.

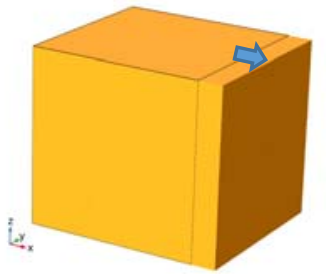

$E_{11}$ Young's modulus $v_{12}$ and $v_{13}$ Poisson's ratio

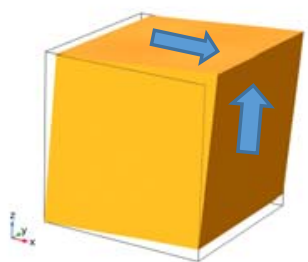

$\mu_{13}$ shear modulus

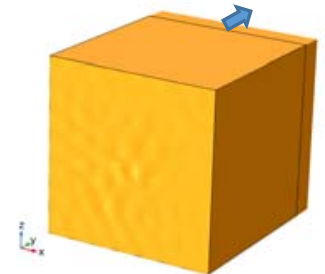

$E_{22}$ Young's modulus $v_{21}$ and $v_{23}$ Poisson's ratio

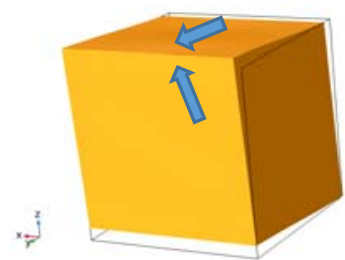

$\mu_{23}$ shear modulus

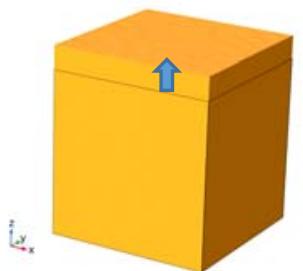

$E_{33}$ Young's modulus $v_{31}$ and $v_{32}$ Poisson's ratio

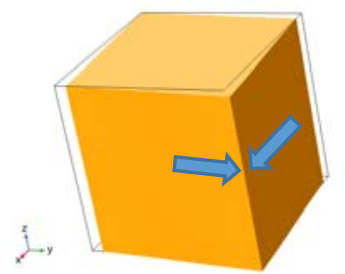

$\mu_{12}$ shear modulus

Figure 2: Boundary conditions applied to the unit cell

It is important to note that continuous/welded contact between the inclusion, interphase and the matrix implied displacement continuity across their interfaces. The stress and strain components were not uniform throughout the heterogeneous structure, and thus were volume-averaged to obtain the average stresses. Using FEM the volume-averaged stresses and strains can be calculated as:

$$
\bar{\sigma}_{i j}=\frac{1}{V} \int_{V} \sigma_{i j} d V
$$




$$
\bar{\varepsilon}_{i j}=\frac{1}{V} \int_{V} \varepsilon_{i j} d V
$$

where $V$ is the volume of the RVE. The averages are then treated as the effective stress and strain fields in the homogenized RVE. The relations between $\sigma_{i j}$ and $\varepsilon_{i j}$ determine the "effective" constitutive law.

\section{Boundary conditions}

In order to fully define the problem at hand, boundary conditions must also be prescribed for the unit-cell domain shown in Fig. 2. To do so, six boundary conditions are required, three tensile and three shear loads, which were selected in order to model the elastic deformation of a computational domain. The approach proposed in [35] is used in this work. For instance, to predict the unknown effective elastic coefficients of stiffness matrix we impose the boundary conditions in such away is not equal to zero and all other strains are zero. The remaining that the macroscopic strain coefficients can be determined in a similar way.

\section{RESULTS AND DISCUSSIONS}

he finite element method is a powerful tool to solve the governing equations over the RVE domain that was discretized with satisfactorily mesh using the boundary conditions given in the previous subsection. Volume averaged stresses and strains were used for the computation of the effective Young's modulus $E^{e f f}$ and the effective shear modulus $\boldsymbol{\mu}^{\text {eff }}$ from Eqns. (10) and (11). For the verification of the exactitude of results, a case of homogeneous composite was studied by putting the same properties for the three-component composite (inclusion, interphase and matrix) with each component. The numerically predicted effective properties Young's modulus and shear modulus were found to be identical to the values of $\mathrm{E}$ and mu of each component.

\section{Convergence of the results with regard to mesh size}

First, mesh convergence was verified by analysing the relative difference in the effective Young's modulus and shear modulus between different meshes. We note that the curves of von Mises stress in the unit cell in all the different meshes tested here (coarse, coarser and extra coarse) have the same appearance in addition they overlap almost completely with negligible differences, see Fig. 3 . The elastic properties and von Mises stress are independent from the mesh size chosen or computation.

Comparison with analytical bounds and estimation

The Voigt and Reuss models give too rough a framework for estimating the effective modules. Voigt's model assumes constant deformation. This model leads to an upper bound for the tensor of the modules of the effective medium. The expression is given by:

$$
\begin{aligned}
& \mu=\mu_{\text {inter }} * P_{\text {inter }}+\mu_{i n c} * P_{\text {inc }}+\mu_{\text {mat }} * P_{\text {mat }} \\
& E=E_{\text {inter }} * P_{\text {inter }}+E_{i n c} * P_{i n c}+E_{\text {mat }} * P_{\text {mat }}
\end{aligned}
$$

For the lower bound, Reuss uses the constant stress. The expression is given by:

$$
\begin{aligned}
& \frac{1}{\mu}=\frac{P_{\text {inter }}}{\mu_{\text {inter }}}+\frac{P_{\text {inc }}}{\mu_{\text {inc }}}+\frac{P}{\mu_{\text {mat }}} \\
& \frac{1}{E}=\frac{P_{\text {inter }}}{E_{\text {inter }}}+\frac{P_{i n c}}{E_{\text {inc }}}+\frac{P}{E_{\text {mat }}}
\end{aligned}
$$




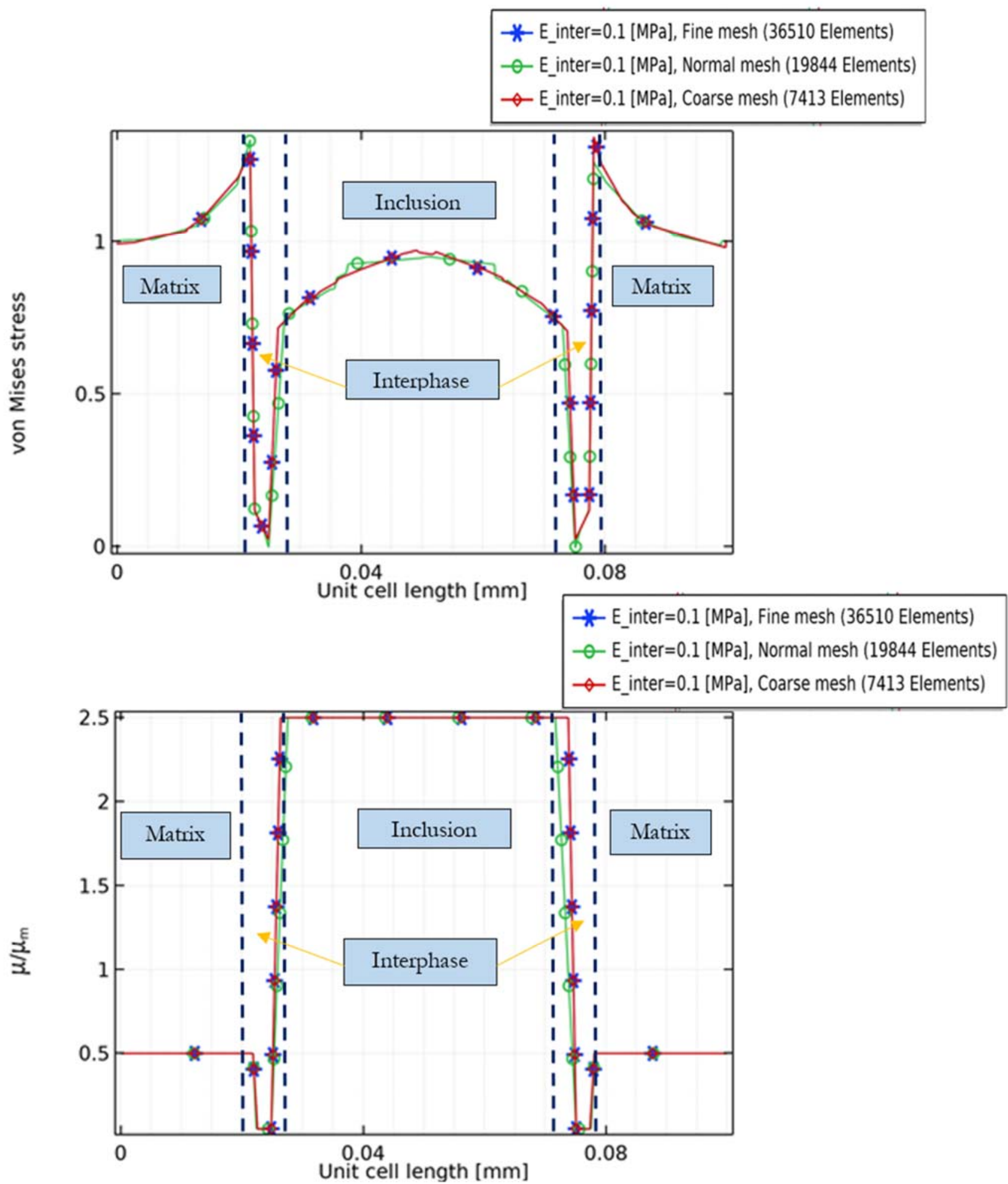

Figure 3: von Misses stress and shear ratio for the case of $10 \%$ as a function of unit cell length for different mesh density ellipsoid interphase morphology (case $10 \%$ case 2 )

Mean-field (MF) homogenization techniques [40,41] describe the composite rheological behavior based on the average stress and strain tensors on phase level and composite level. In the MF approach, the problem of a composite with coated inclusions can be seen as a three-phase composite. Model's prediction in this research is based on the first order Mori- 
Tanaka homogenization (MTH) technique. The inclusions are first homogenized with their coatings (first level of homogenization), and the resulting material, which can be seen as an "effective inclusion", is then homogenized with the matrix (second level of homogenization), see Fig. 4.

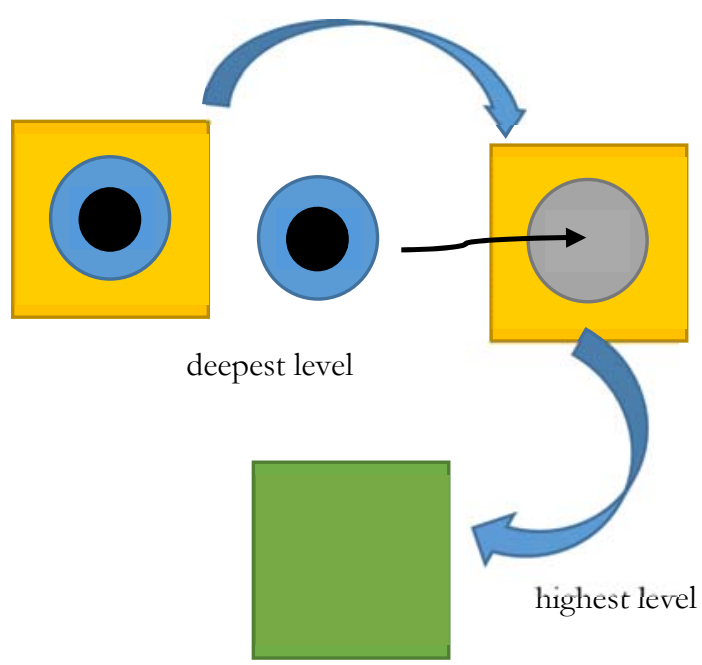

Figure 4: Multi-level homogenization

The MFH approach is a fast (requires no generation of RVE model and meshing) and efficient way to forecast the effective elastic properties of linear elastic composites. The mean-field stress $(\sigma)$ and strain $(\varepsilon)$ in each phase $i$ and associated parameters are given in [42].

Figs. 5, 6 and 7 plots the ratio of Young's modulus and shear modulus of the composite, to the matrix Young's modulus and shear modulus, as a function of interphase Young's modulus for two different interphase morphology spherical and ellipsoids morphologies. We note that the lower bound of Reuss gives very good results compared to the finite elements computation results for the case of prediction of shear modulus. The results are independent of the kinds of interphases morphology. The Mean-field (MF) homogenization technique give a good agreement with the finite elements estimation of the Young's modulus but it presents a big difference in the case of shear modulus equal to $25 \%$ in the case of spherical interphase morphology. For the case of ellipsoid interphase morphology, it is equal to $15 \%$.

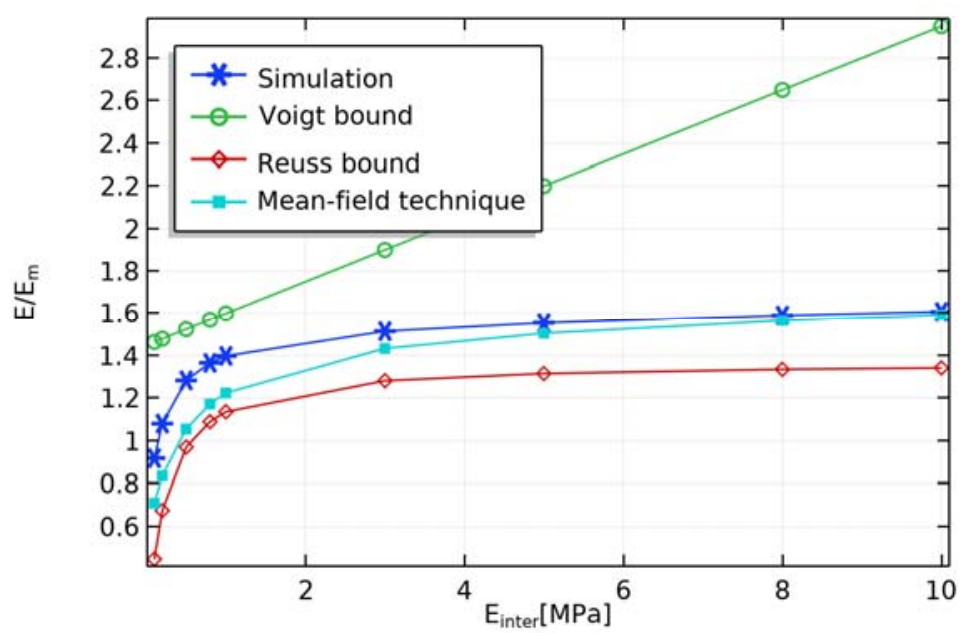

Figure 5: Effect of the interphase Young's modulus $\boldsymbol{E}_{\boldsymbol{i n t e r}}$ on the ratio of the composite Young's modulus, $\boldsymbol{E}$ to the matrix Young's modulus, $\boldsymbol{E}_{\boldsymbol{m}}$ for ellipsoid interphase morphology at a constant volume fraction of $30 \%$ case 1. 


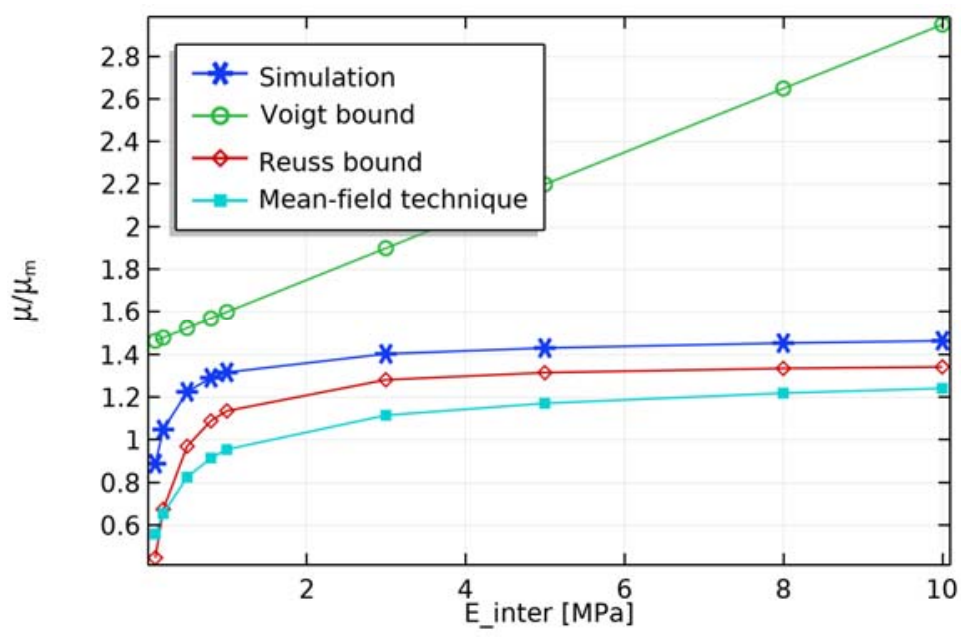

Figure 6: Effect of the interphase Young's modulus $\boldsymbol{E}_{\text {inter }}$ on the ratio of the composite shear modulus, $\mu$ to the matrix shear modulus, $\boldsymbol{\mu}_{\boldsymbol{m}}$ for ellipsoid interphase morphology at a constant volume fraction of $30 \%$ case 1.

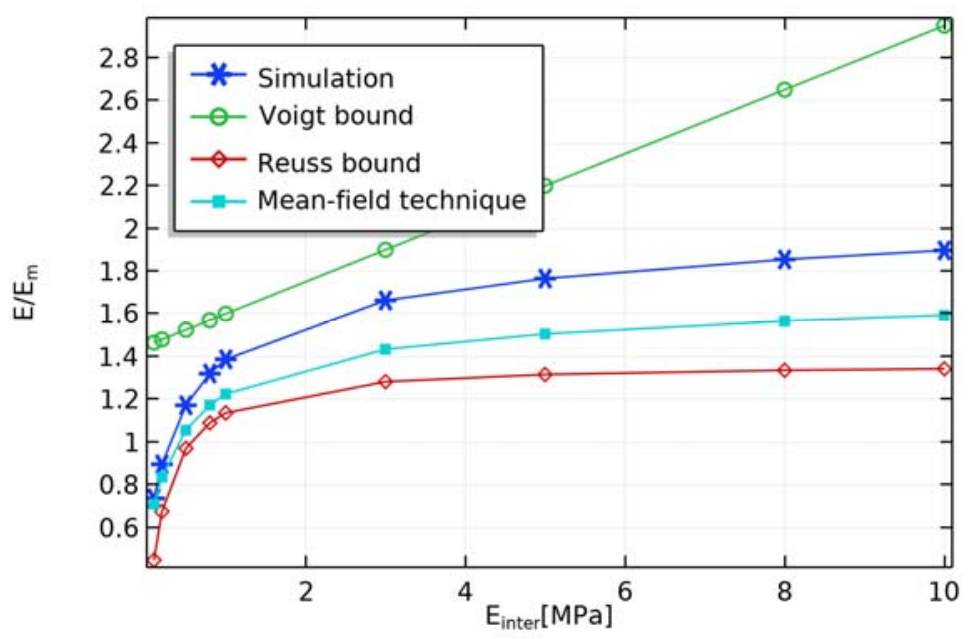

Figure 7: Effect of the interphase Young's modulus $\boldsymbol{E}_{\boldsymbol{i n t e r}}$ on the ratio of the composite Young's modulus, $\boldsymbol{E}$ to the matrix Young's modulus, $\boldsymbol{E}_{\boldsymbol{m}}$ for spherical interphase morphology at a constant volume fraction of $30 \%$ case 1 .

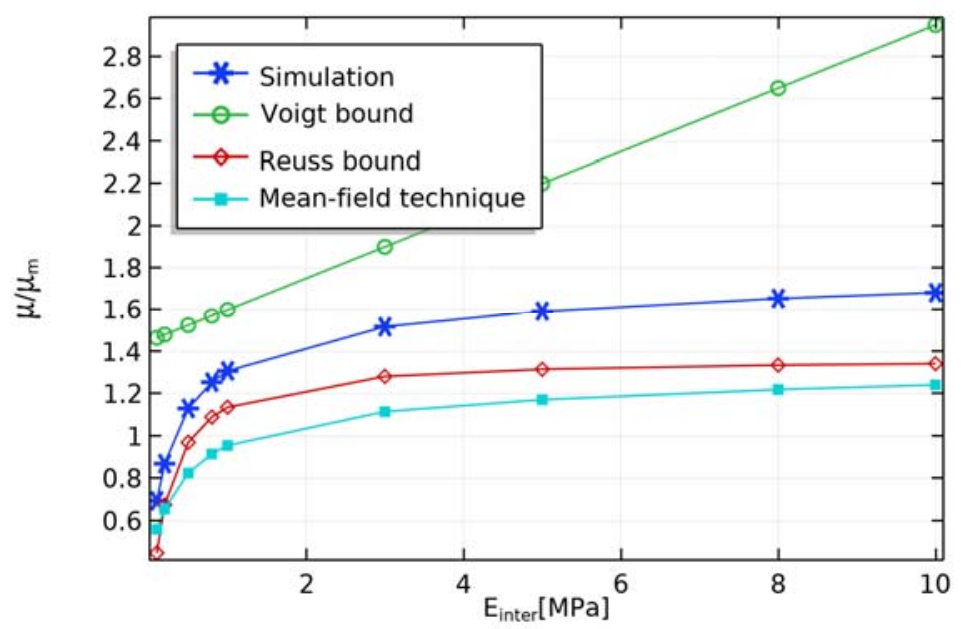

Figure 8: Effect of the interphase Young's modulus $\boldsymbol{E}_{\text {inter }}$ on the ratio of the composite shear modulus, $\mu$ to the matrix shear modulus, $\boldsymbol{\mu}_{\boldsymbol{m}}$ for spherical interphase morphology at a constant volume fraction of $30 \%$ case 1 . 


\section{Effect of interphase volume fraction}

Figs. 8, 9, 10,11,12,13 and 14 plots the ratio in Young's modulus and shear modulus as a function of the interphase Young's modulus ranging from 0,1 to 10 . The ratio $\boldsymbol{E} / \boldsymbol{E}_{\boldsymbol{m}}$ and $\boldsymbol{\mu} / \boldsymbol{\mu}_{\boldsymbol{m}}$ is presented for three volume fractions and different interphase morphology. It is interesting to note here that the ratio $\boldsymbol{E} / \boldsymbol{E}_{\boldsymbol{m}}$ depends on the interphase Young's modulus and considerably with the morphology of the interphase. For the contrast greather than 3, the curves are nearly linear and stable. But for the contrast less than 3 , we note a big gain in elastic properties.

It is also observed that for the big volume fractions of inclusions and interphase, the Young's modulus and shape affect considerably the elastic properties of composite materials, see figures. For the cases of soft interphase, the amelioration for the case of 5\% in Young's and shear modulus is about 5\% compared to the amelioration in other cases study of 10 and $30 \%$ are about 10 and $35 \%$ respectively. We also note a divergence of results between the cases studied especially for the volume fractions $30 \%$ but with less effect for the volume fractions 5 and $10 \%$.

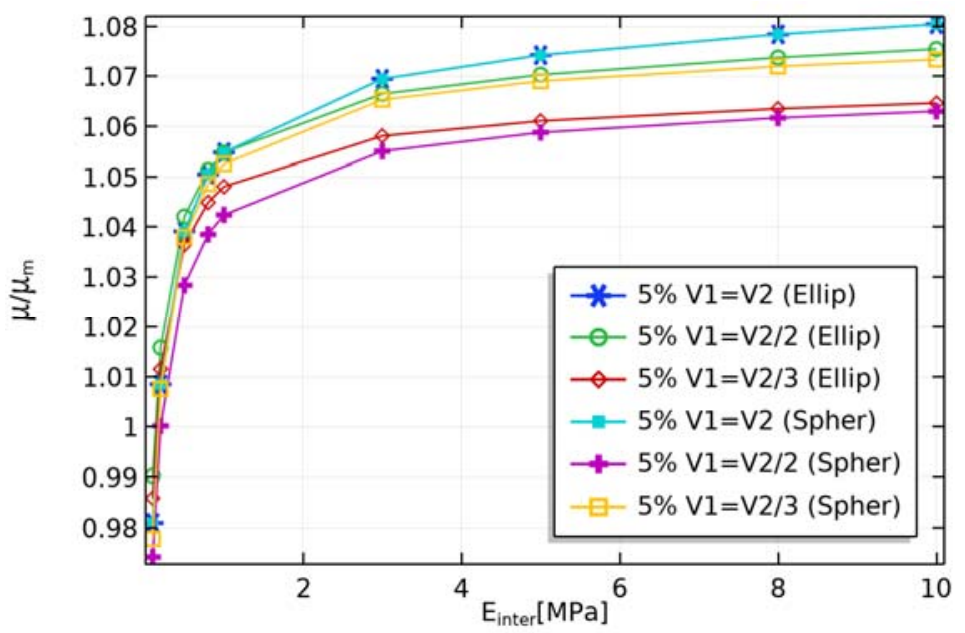

Figure 9: Effect of the interphase Young's modulus $\boldsymbol{E}_{\text {inter }}$ on the ratio of the composite shear modulus, $\mu$ to the matrix shear modulus, $\boldsymbol{\mu}_{\boldsymbol{m}}$ for different interphase morphology at a constant volume fraction of $5 \%$.

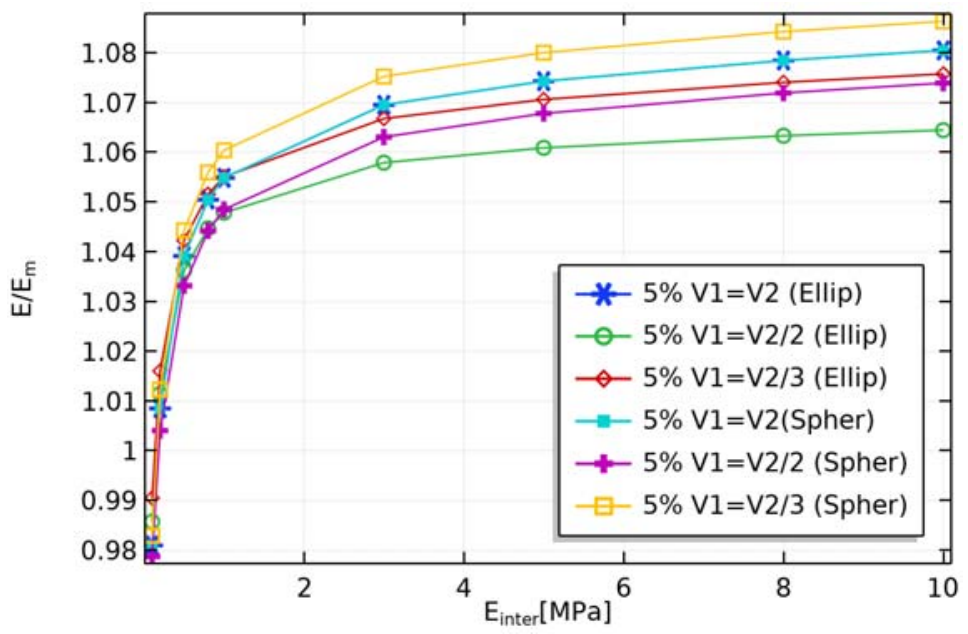

Figure 10: Effect of the interphase Young's modulus $\boldsymbol{E}_{\boldsymbol{i n t e r}}$ on the ratio of the composite Young's modulus, $\boldsymbol{E}$ to the matrix Young's modulus, $\boldsymbol{E}_{\boldsymbol{m}}$ for different interphase morphology at a constant volume fraction of 5\%.

For the cases of stiff interphase, the amelioration for the case of 5\% in Young's and shear modulus is about $8 \%$ compared to the amelioration in other cases study of 10 and $30 \%$ are about 16 and $60 \%$ respectively. 


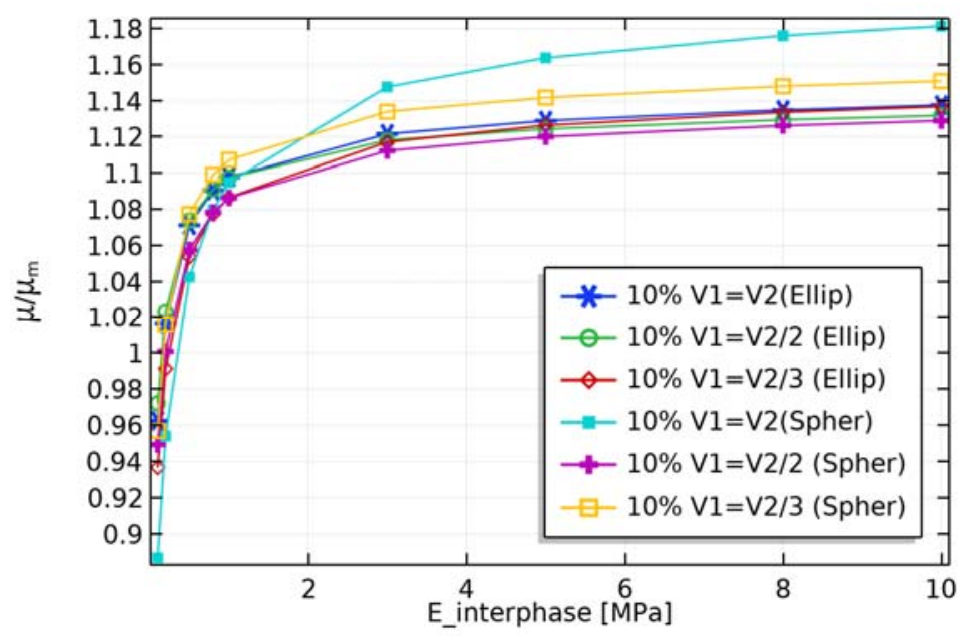

Figure 11: Effect of the interphase Young's modulus $\boldsymbol{E}_{\boldsymbol{i n t e r}}$ on the ratio of the composite shear modulus, $\mu$ to the matrix shear modulus, $\boldsymbol{\mu}_{\boldsymbol{m}}$ for different interphase morphology at a constant volume fraction of $10 \%$.

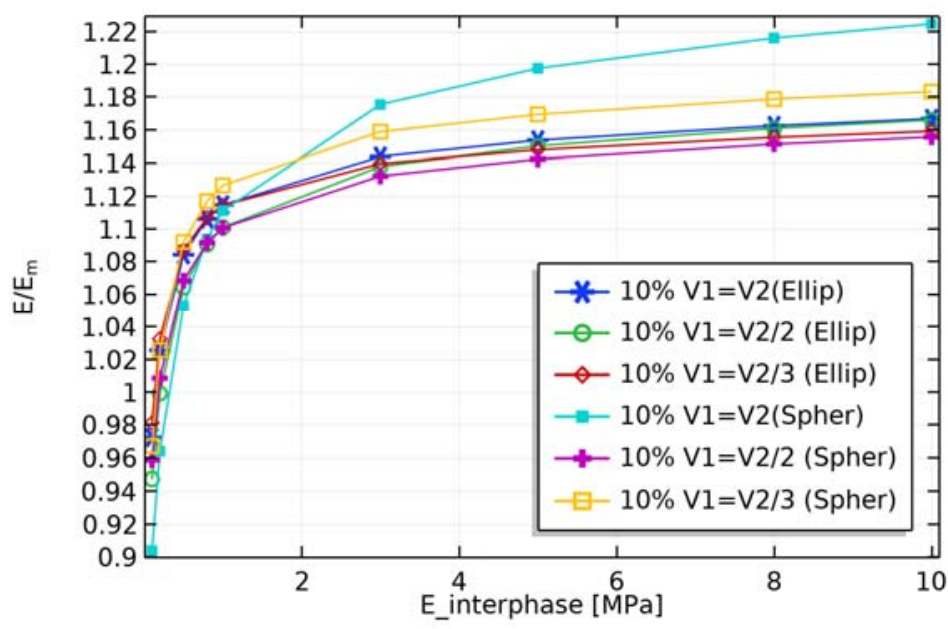

Figure 12: Effect of the interphase Young's modulus $\boldsymbol{E}_{\boldsymbol{i n t e r}}$ on the ratio of the composite Young's modulus, $\boldsymbol{E}$ to the matrix Young's modulus, $\boldsymbol{E}_{\boldsymbol{m}}$ for different interphase morphology at a constant volume fraction of $10 \%$.

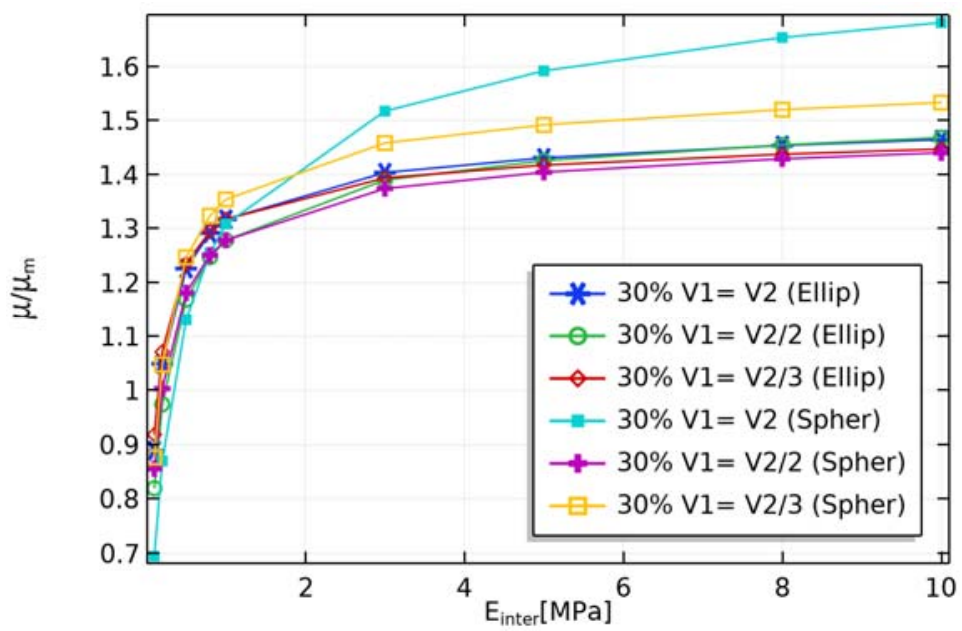

Figure 13: Effect of the interphase Young's modulus $\boldsymbol{E}_{\boldsymbol{i n t e r}}$ on the ratio of the composite shear modulus, $\mu$ to the matrix shear modulus, $\boldsymbol{\mu}_{\boldsymbol{m}}$ for different interphase morphology at a constant volume fraction of $30 \%$. 


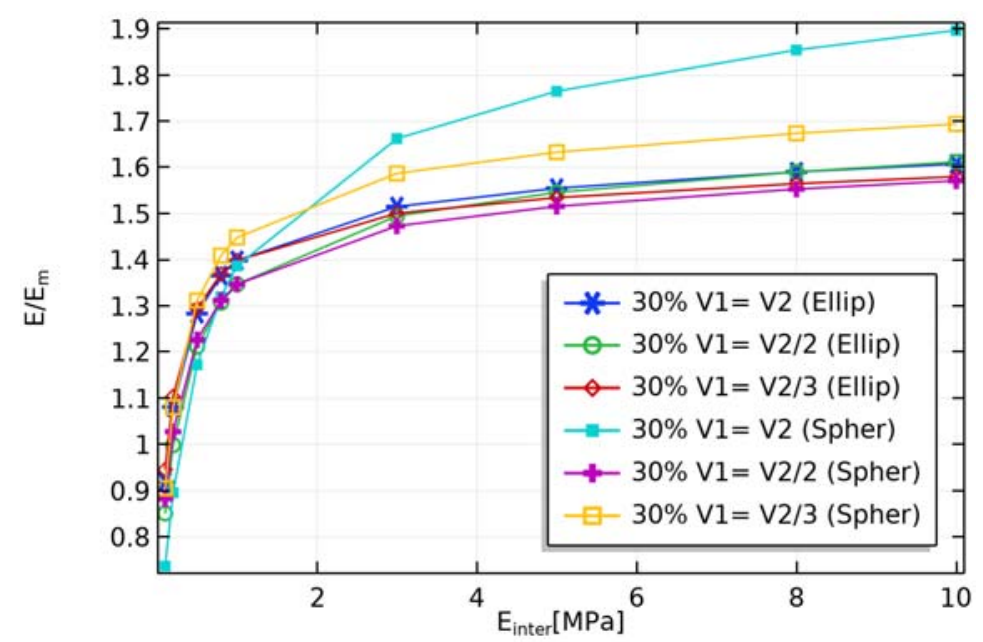

Figure 14: Effect of the interphase Young's modulus $\boldsymbol{E}_{\boldsymbol{i n t e r}}$ on the ratio of the composite Young's modulus, $\boldsymbol{E}$ to the matrix Young's modulus, $\boldsymbol{E}_{\boldsymbol{m}}$ for different interphase morphology at a constant volume fraction of $30 \%$.

\section{Effect of interphase morphology}

In this section, we discuss the influence of morphological parameters namely interphase shape and volume fraction of this phase on the effective Young's and shear modulus of the three phases material. With the variation of volume of interphase from $1,1 / 2$ and $1 / 3$ times the inclusion volume, we note here the increase of the elastic properties (bulk and shear modulus) in all the cases for spherical and ellipsoid interphase.

In all the cases, for the soft interphase compared to the matrix stiffness, for all the volumes fractions and morphologies, the elastic properties are independent. For the stiff interphase compared to the matrix stiffness, the 1 times for all the volumes fraction and morphology presents better properties compared to the others volume $1 / 2$ and $1 / 3$ times, see Fig. 8, 9, 10, 11, 12,13 and 14 .

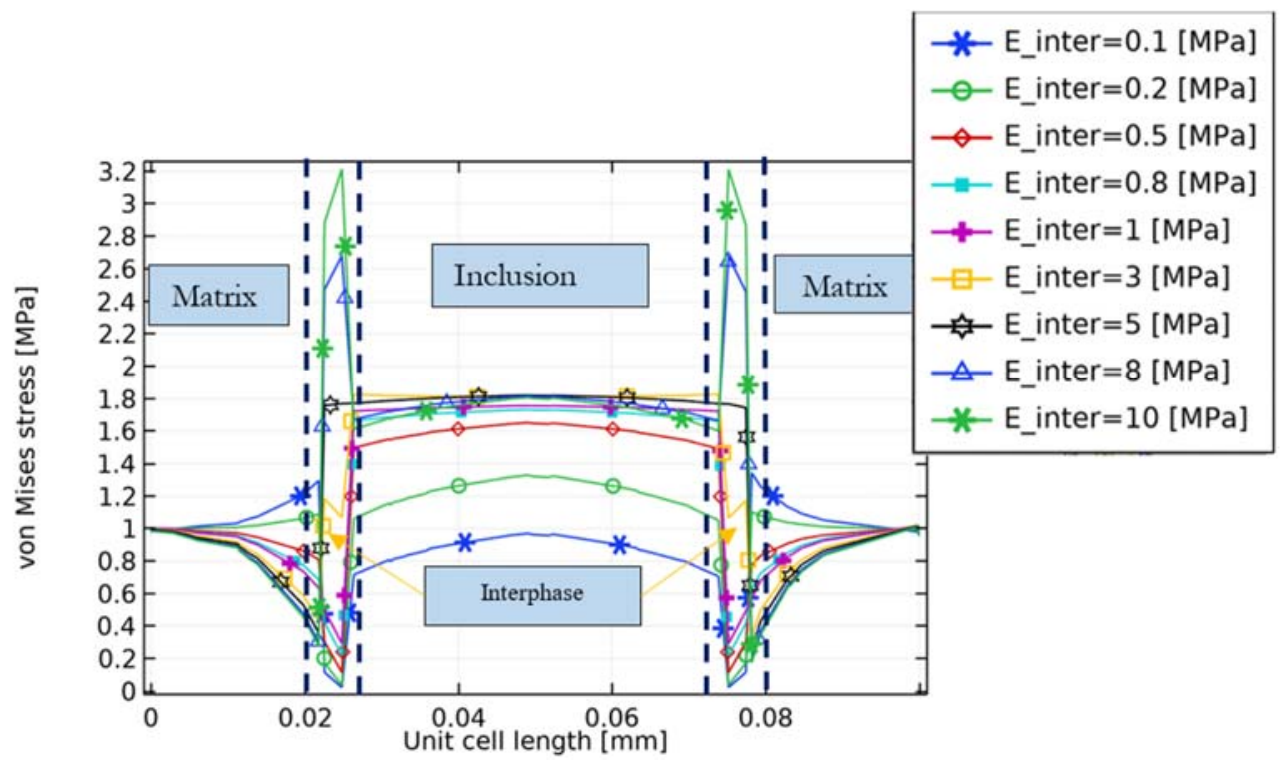

Figure 15: Von Mises stress for the case of $10 \%$ as a function of interphase Young's modulus for ellipsoid interphase morphology (case $10 \%$, case 2).

\section{Effect of interphase Young's modulus on the Von Mises stress}

Fig. 15, 16 shows the evolution of the VM stress in a section made through the center of the unit cell. This in order to be able to trace the constraint in the three elements (matrix, inclusion and interphase). In the outside of the interphase region, it is important to say that all the curves for different interphase Young's modulus for the two cases of ellipsoid and spherical interphase morphologies have the same appearance. The maximum of Von Mises stress are observed in the interphase area. 
This value is located for the case with interphase young modulus equal to 8 and $10[\mathrm{MPa}]$ for the ellipsoid and spherical interphase morphology.

In addition to the interphase, all the von Mises stress curves converge towards the value of 1 [MPa], the matrix Young's modulus value. The von Mises is small in the interval [0.1, 0.2], while on the other hand in the interval $[0.5,5]$ they exceed the stress found in the matrix. We note that the value of Von Mises stress in the two cases of ellipsoid and spherical interphase morphologies nearly present the same value with a small growth for the ellipsoid interphase.

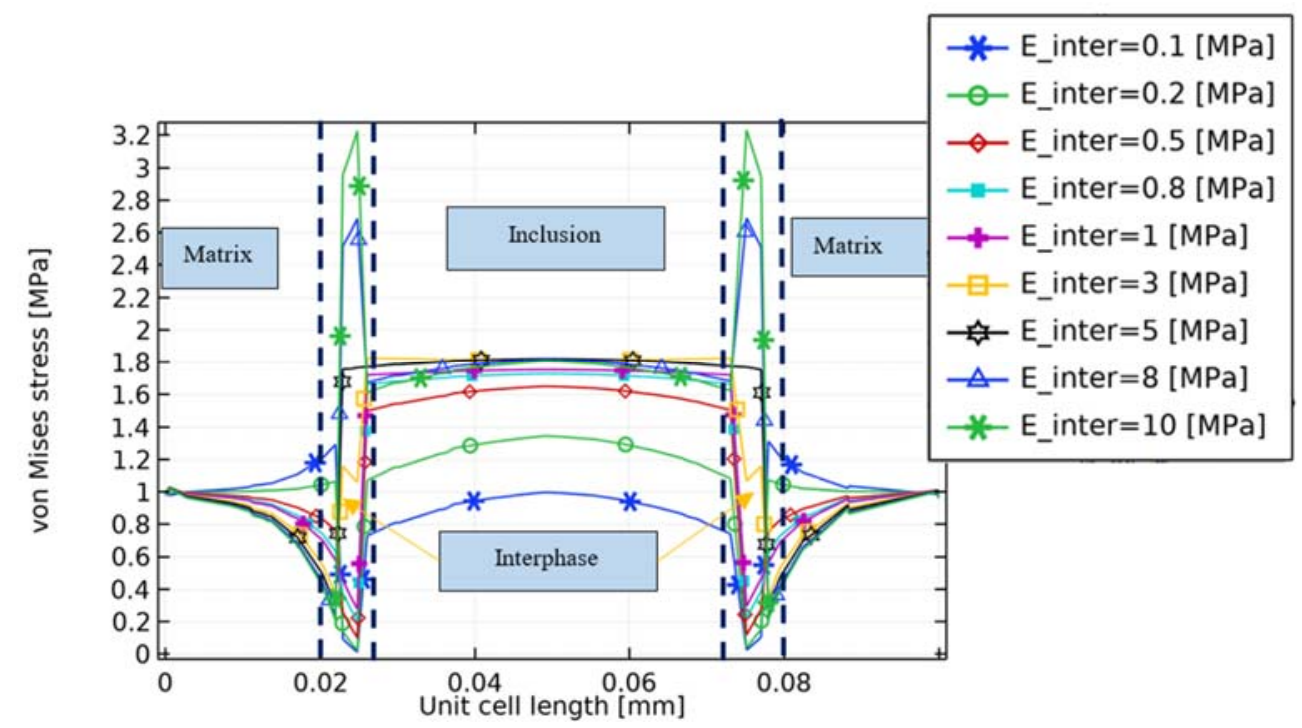

Figure 16: Von Mises stress for the case of $10 \%$ as a function of interphase Young's modulus for spherical interphase morphology (case $10 \%$, case 2 )

Fig. 17 plots the stress in the three components of the composite, in the case of shear computation for the Von Mises stress for the case of $30 \%$ (case 1) for spherical and ellipsoid interphase morphology and interphase Young's modulus equal to 10 [MPa].

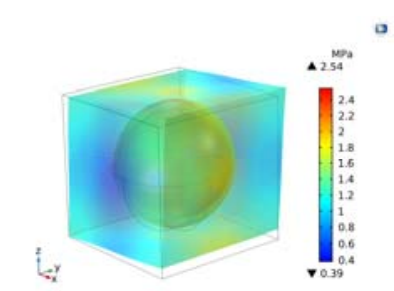

Unit cell

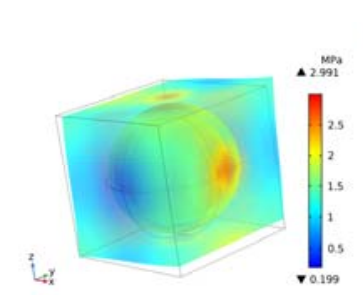

Unit cell

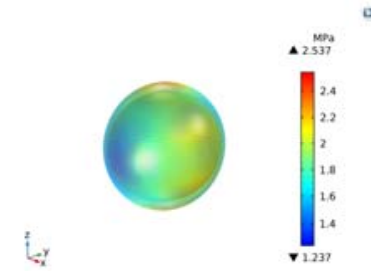

Interphase Ellipsoid interphase

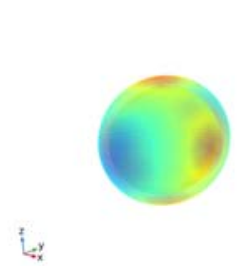

Interphase

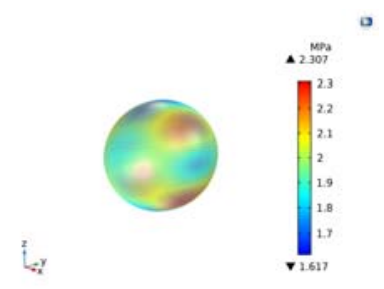

Inclusion

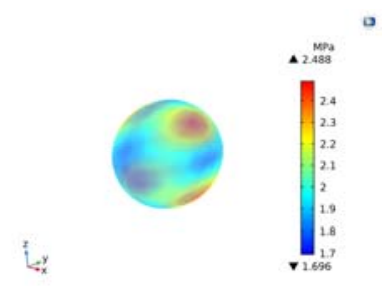

Inclusion Spherical interphase

Figure 17: von Mises stress for the case of $30 \%$ (case 1) for spherical and ellipsoid interphase morphology and interphase Young's modulus E_interphase $=10[\mathrm{MPa}]$

In the case where the interphase Young's modulus is equal to matrix Young's modulus, Fig. 17 presents the stress in the different domains of the unit cell (matrix, interphase and inclusion) in the case of computation of shear modulus (case $30 \%$, 
case 1). For spherical interphase morphology, the Von Mises stress value is the same in the two cross-section planes (ZX and $\mathrm{ZY}$ ), see Fig. 18.

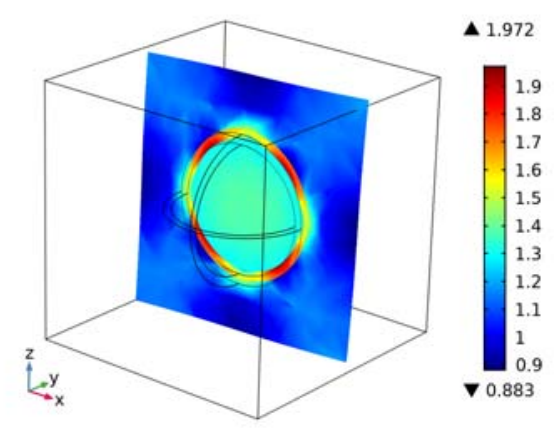

$\square$

口

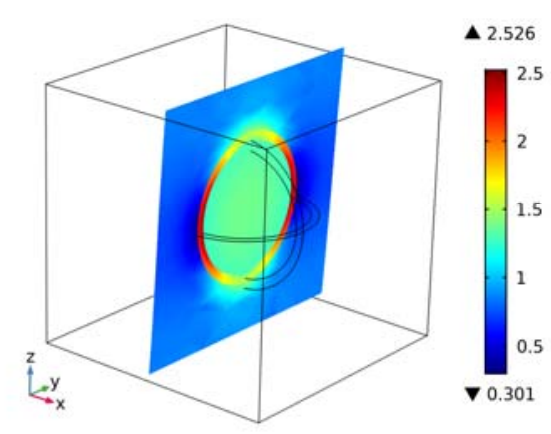

a

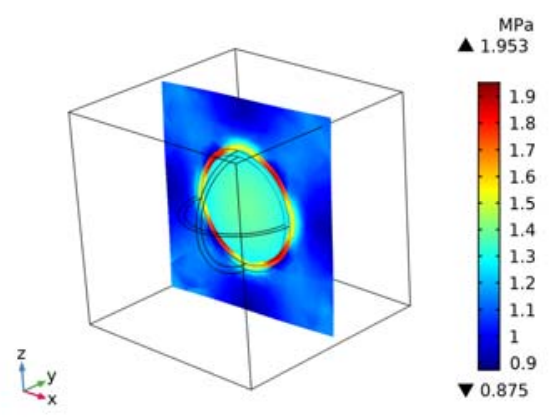

口

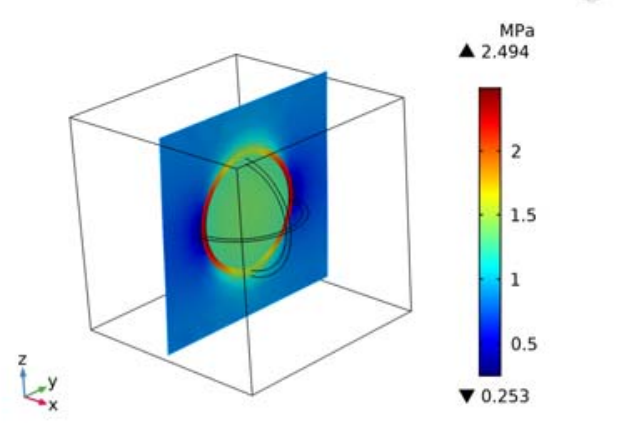

Ellipsiod E_interphase $=10[\mathrm{MPa}] \quad$ Spherical E_interphase $=10[\mathrm{MPa}]$

Figure 18: von Mises stress as a function of interphase Young's modulus for spherical and ellipsoid interphase morphology (case 10\%, case 2)

a
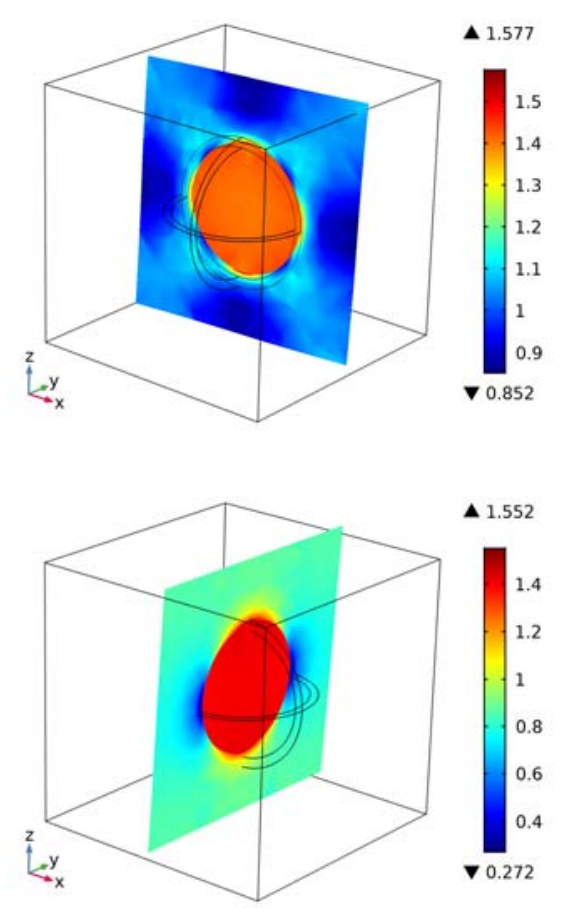

Ellipsiod E_interphase $=1[\mathrm{MPa}]$

口

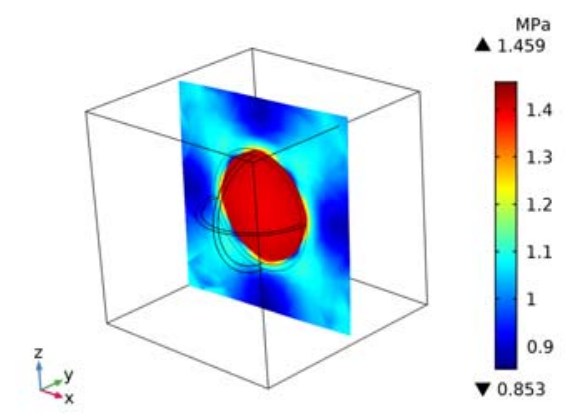

Spherical E_interphase $=1[\mathrm{MPa}]$

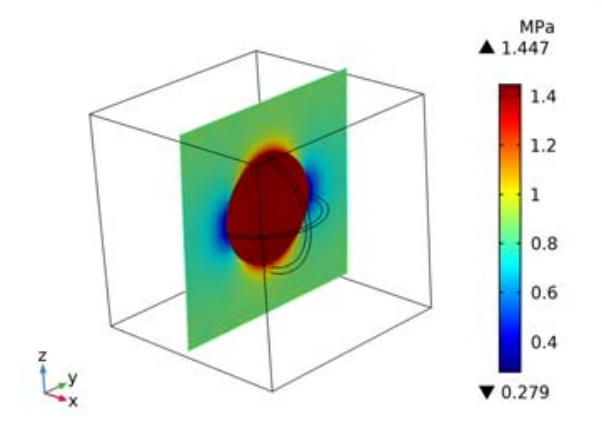

口

口 Figure 19: von Mises stress as a function of interphase Young's modulus for spherical and ellipsoid interphase morphology (case 10\%, case 2). 
For the ellipsoid interphase, we note a difference between the von Mises results in the two cross-section planes (ZX and $\mathrm{ZY})$, see Fig.18. It is a logical conclusion because of the shape of the ellipse which has three rays $(r, r, R)$ according to the three dimensions.

It is very important to know the location of the maximum stress, for that many simulations were conducted. A lot of parameters are tested in this work by varying the interphase Young's modulus from 0.1 to 10 [MPa].

Fig.18 plots the stress for the case where we have a stiff interphase, that means the interphase Young's modulus is equal to 10 times the matrix Young's modulus (E_interphase $=10[\mathrm{MPa}])$. In this case, the maximum stress is located in the region of interphase area for all the morphologies.

Fig. 19 plots the stress for the case of interphase Young's modulus is equal to the matrix Young's modulus (E_interphase = $1[\mathrm{MPa}])$. In this case, the maximum stress is located in the region of inclusion inside the interphase area for all the morphologies.

口

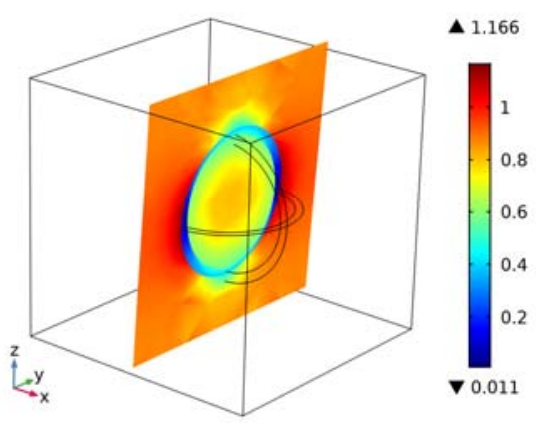

口

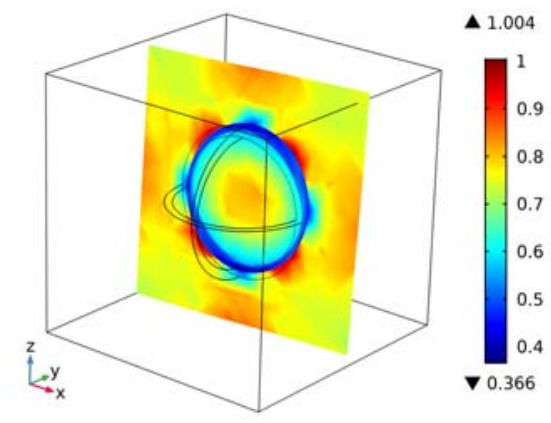

Ellipsiod E_interphase $=0.1[\mathrm{MPa}]$
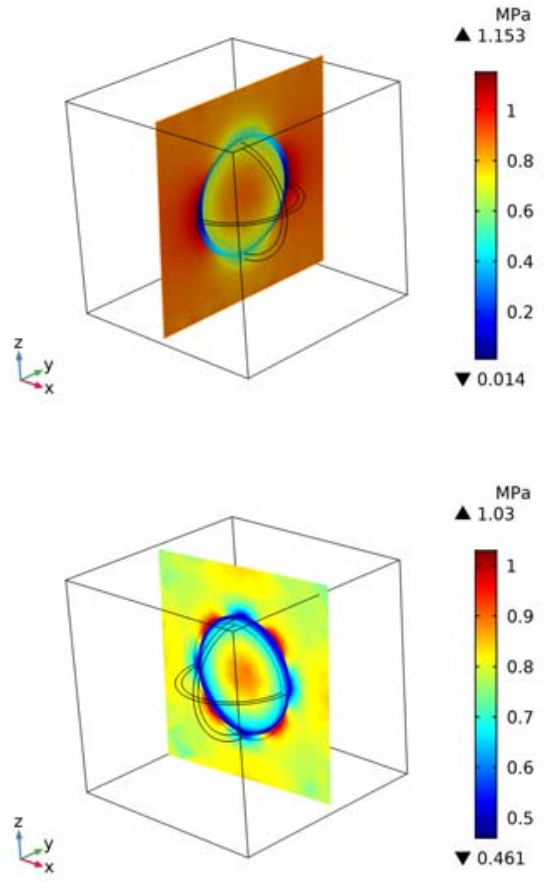

Spherical E_interphase $=0.1[\mathrm{MPa}]$

Figure 20: Von-Mises stress as a function of interphase Young's modulus for spherical and ellipsoid interphase morphology (case 10\%, case 2).

Fig. 20 plots the stress for the case of soft interphase (E_interphase $=0.1[\mathrm{MPa}]$ ). For the soft interphase, the maximum stress is located in the region around the outdoor interphase for all the morphologies. It should be pointed out here that it is according to the direction (planes XY, ZY, XZ) and the type of loading, the stresses follow the direction.

\section{CONCLUSION}

A new model based on the unit cell approach is proposed to the estimation of effective elastic properties of threephase coated spherical inclusion using homogenization techniques and finite elements method for different volume fractions and different interphase morphology. Two different representative volume elements were created and finite element analysis using kinematic uniform boundary conditions was performed. The effective elastic constants have been calculated with the finite element model. The numerical results demonstrate that the developed FEM approach is very useful and give good and efficient results for the analysis of unit cell models of composite, with the presence of the interphases. 
We observed that for the big volume fractions of inclusions and interphase, the Young's modulus and interphase shape affect considerably the elastic properties of composite materials. With the variation of volume of interphase from $1,1 / 2$ and $1 / 3$ times the inclusion volume, we note here the increase of the elastic properties (bulk and shear modulus) in all the cases for spherical and ellipsoid interphase. We note here that the value of Von Mises stress in the two cases of ellipsoid and spherical interphase morphologies nearly present the same value with a small growth for the ellipsoid interphase. The maximum of Von Mises stress are observed in the interphase area. This value is located for the case with interphase young modulus equal to 8 and $10[\mathrm{MPa}$ ] for the ellipsoid and spherical interphase morphology.

The present work has laid down a foundation for further applications of micro-mechanical model analysis for problems, such as an investigation of stress field in the interphase for the study of inelastic behavior in this area. In addition, this model offers opportunities to study the behavior of the interphase in temperatures fields.

\section{REFERENCES}

[1] Benjamin, A. Y., Gaurav, S., Amanda, M. F. K., Alexander, M. T., Aditya, K., Ertugrul, T., Laurent P., (2016). Effective elastic moduli of core-shell-matrix composites, Mechanics of Materials 92, pp. 94-106.

DOI: $10.1016 /$ j.mechmat.2015.09.006.

[2] Benjamin, A. Y., Zhenhua, W., Jose, R. C., Gabriel, F., Aditya, K., Narayanan, N.,Gaurav, S., Laurent, P., (2017). A general method for retrieving thermal deformation properties of microencapsulated phase change materials or other particulate inclusions in cementitious composites. Materials \& Design, 126, pp. 259-267.

DOI: $10.1016 /$ j.matdes.2017.04.023.

[3] Ling, T.C., Poon, C.S., (2013). Use of phase change materials for thermal energy storage in concrete: An overview. Constr. Build. Mater. 46, pp. 55-62. DOI : 10.1016/j.conbuildmat.2013.04.031.

[4] Ghosh, S. K., (2009). Self-Healing Materials: Fundamentals, Design Strategies, and Applications. John Wiley \& Sons.

[5] Tyagi, V. V., Kaushik, S. C., Tyagi, S. K., Akiyama, T., 2011. Development of phase change materials based microencapsulated technology for buildings: a review. Renew. Sustain. Energy Rev. 15(2), pp. 1373-1391. DOI: $10.1016 /$ j.rser.2010.10.006

[6] Cabeza, L. F., Castellon, C., Nogues, M., Medrano, M., Leppers, R., Zubillaga, O., (2007). Use of microencapsulated PCM in concrete walls for energy savings. Energ. Build. 39(2), pp. 113-119. DOI: 10.1016/j.enbuild.2006.03.030.

[7] Eroshkin, O., Tsukrov, I., (2005). On micromechanical modeling of particulate composites with inclusions of various shapes. International Journal of Solids and Structures, 42, pp. 409-427. DOI : 10.1016/j.ijsolstr.2004.06.045.

[8] Ghossein, E., Lévesque, M., (2012). A fully automated numerical tool for a comprehensive validation of homogenization models and its application to spherical particles reinforced composites. International Journal of Solids and Structures, 49, pp. 1387-1398. DOI: 10.1016/j.ijsolstr.2012.02.021.

[9] Gusev, A., (2014). Effective coefficient of thermal expansion of $n$-layered composite sphere model: Exact solution and its finite element validation. International Journal of Engineering Science, 84, pp. 54-61. DOI: $10.1016 / 0020-7225(86) 90162-X$.

[10] Giordano, S., (2016). Nonlinear effective behavior of a dispersion of randomly oriented coated ellipsoids with arbitrary temporal dispersion. International Journal of Engineering Science, 98, pp. 14-35. DOI: 10.1016/j.ijengsci.2015.07.009.

[11] Cherkaoui, M., Sabar, H., Berveiller, M., (1994). Micromechanical approach of the coated inclusion problem and applications to composite materials. Journal of Engineering Materials and Technology, 116, pp. 274-278.

DOI: $10.1115 / 1.2904286$

[12] Sevostianov, I., Kachanov, M., (2007). Effect of interphase layers on the overall elastic and conductive properties of matrix composites. Application to nanosize inclusion. International Journal of Solids and Structures, 44, pp. 1304-1315. DOI: 10.1016/j.ijsolstr.2006.06.020

[13] Yang, Q. S., Tao, X., Yang, H., (2007). A stepping scheme for predicting effective properties of the multi-inclusion composites. Int. J. Eng. Sci., 45(12), pp. 997-1006. DOI: 10.1016/j.ijengsci.2007.07.005.

[14] Jia, C., Chen, Y., and Huang, Z., (2015), Iterative Method to Predict Effective Elastic Moduli of Multiphase Particulate Composites. J. Eng. Mech., 10, 1061. DOI: 10.1061/(ASCE)EM.1943-7889.0000912.

[15] Bonfoh, N., Hounkpati, V., Sabar, H., (2012). New micromechanical approach of the coated inclusion problem: Exact solution and applications. Computational Materials Science, 62, pp. 175-183.

DOI: 10.1016/j.commatsci.2012.05.007.

[16] Boutaani, M.S., Madani, S., Fedaoui, K, Kanit, T., (2017). Evaluation of effective mechanical properties of complex multiphase materials with finite element method, U.P.B. Sci. Bull., Series D, 79(3). 
[17] Surendra, B., Meenakshi, S., Shashank, B., (2019). Mechanical property evaluation of composites based on $n+1$ phase model and Mori-Tanaka theory, J. Eng. Mech., 145(3), 04018139.

DOI: 10.1061/(ASCE)EM.1943-7889.0001564.

[18] Chaibainou, L., Boutaani, M. S., Fedaoui, K., Chebbah, M. S., (2019). Evaluation of thermal expansion of (Al-SiC) material using homogeneization method coupled to finite element method, U.P.B. Sci. Bull., Series D, 81(4).

[19] Garboczi, E. J., Berryman, J. J, (2001), elastic moduli of material containing composite inclusions:effective medium theory and finite element computations, Mechanics of Materials. 33, pp.455-470.

[20] Iacoviello, F., Cocco, V. D., Bellini, C., (2019), Fatigue crack propagation and damaging micromechanisms in Ductile Cast Irons International Journal of Fatigue, 124, pp. 48-54. DOI: 10.1016/j.ijfatigue.2019.02.030.

[21] Kayal, P. S., Ramanujan, R. V., (2010). Anti-Cancer Drug Loaded Iron-Gold Core-Shell Nanoparticles (Fe/Au) for Magnetic Drug Targeting, Journal of Nanoscience and Nanotechnology, 10, pp.5527-5539.

DOI: $10.1166 /$ jnn.2010.2461.

[22] Pancorbo, P. M., Thummavichai, K., Clark, L., Tanveer, A. Tabish, Jessica, M., Gardner, B., Hong, C., Nick, S., Yanqiu, Z., (2019). Novel Au-SiO2-WO3 Core-Shell Composite Nanoparticles for Surface-Enhanced Raman Spectroscopy with Potential Application in Cancer Cell Imaging, Adv. Funct. Mater. 1903549.

DOI : $10.1002 /$ adfm.201903549

[23] Tijun, C., Libo, G., He, Q., Min, G., 2018. Core-Shell-Structured Particle Reinforced A356 Matrix Composite Prepared by Powder-Thixoforming: Effect of Reheating Temperature. Materials, 11, 1718. DOI: 10.3390/ma11091718.

[24] Abu Taqa, A. G., Abu Al-Rub, R. K., Senouci, A., Al-Nuaimi, N., Bani-Hani, K. A., (2015), The Effect of Interfacial Transition Zone Properties on the Elastic Properties of Cementitious Nanocomposite Materials, Journal of Nanomaterials Volume, Article ID 258384, 13 pages. DOI: 10.1155/2015/258384.

[25] Kim, B. S., Randall, L. T., (2015). The Development of Smart, Multi-Responsive Core/Shell Composite Nanoparticles, Nanoparticles Technology. DOI: 10.5772/61262.

[26] Voigt, W., (1889). Ueber die Beziehung zwischen den beiden Elasticitätsconstanten isotroper Körper. Annalen der Physik. 274. pp. 573-587. DOI : 10.1002/andp.18892741206.

[27] Reuss, A., (1929). Berechnung der Fließgrenze von Mischkristallen auf Grund der Plastizitätsbedingung für Einkristalle. Zeitschrift für Angewandte Mathematik und Mechanik. 9, pp. 49-58. DOI: 10.1002/zamm.19290090104.

[28] Walpole, L. J., (1978), A Coated Inclusion in an Elastic Medium, Math. Proc. Cambridge Philos. Soc.0305-0041, 83, pp. 495-506. DOI: $10.1017 /$ S0305004100054773.

[29] Aboutajeddine, A., Neale, K., (2005). The double-inclusion model: A new formulation and new estimates. Mechanics of Materials, 37, pp. 331-341. DOI: 10.1016/j.mechmat.2003.08.016.

[30] Benveniste, Y., (1987). A new approach to the application of Mori-Tanaka's theory in composite materials. Mechanics of Materials, 6, pp. 147-157. DOI: 10.1016/0167-6636(87)90005-6.

[31] Benveniste, Y., Dvorak, G., Chen, T., 1991. On diagonal and elastic symmetry of the approximate effective stiffness tensor of heterogeneous media. Journal of the Mechanics and Physics of Solids, 39, pp. 927-946.

DOI: 10.1016/0022- 5096(91)90012-D.

[32] Hervé, E., Zaoui, A., (1995). Elastic behaviour of multiply coated fibre-reinforced composites. International Journal of Engineering Science. 33(10), pp. 1419-1433. DOI: 10.1016/0020-7225(95)00008-L.

[33] Hervé, E., \& Zaoui, A., (1993). N-layered inclusion-based micromechanical modelling. International Journal of Engineering Science, 31, pp. 1-10. DOI : 10.1016/0020-7225(93)90059-4.

[34] Lipinski, P, Barhdadi, E. H., Cherkaoui, M., (2006), Micromechanical modelling of an arbitrary ellipsoidal multicoated inclusion, Philosophical Magazine, 86(10), pp. 1305-1326. DOI: 10.1080/14786430500343868.

[35] Berger, H., Kurukuri, S., Kari, S., Gabbert, U., Rodriguez-Ramos, R., Bravo-Castillero, J. and Guinovart-Diaz, R., (2007). Numerical and Analytical Approaches for Calculating the Effective Thermo-Mechanical Properties of ThreePhase Composites', Journal of Thermal Stresses, 30(8), pp. 801-817. DOI: 10.1080/01495730701415665.

[36] Alexander, M. T., Aditya, K., Gaurav, S., Laurent, P., (2014). Effective thermal conductivity of three-component composites containing spherical capsules International Journal of Heat and Mass Transfer 73, pp. 177-185.

DOI : 10.1016/j.ijheatmasstransfer.2014.02.002.

[37] Böhm, H. J., (2019), Comparison of analytical and numerical models for the thermoelastic behavior of composites reinforced by coated spheres, International Journal of Engineering Science 142, pp. 216-229. DOI: 10.1016/j.ijengsci.2019.06.009.

[38] Amraei, J., Jafar, E J, Behrouz, A., Roohollah, D. F. A., (2018). Effect of interphase zone on the overall elastic properties of nanoparticle reinforced polymer nanocomposites, Journal of Composite Materials 0(0), pp. 1-14.

DOI: $10.1177 / 0021998318798443$. 
[39] Hjelmstad, K. D., (2005), Fundamentals of Structural Mechanics (Second edition). Springer.

[40] Pierard, O., Friebel, C., Doghri, I., (2004), Mean-field homogenization of multi-phase thermo-elastic composites: a general framework and its validation, Compos. Sci. Technol., 64(10-11), p1587-1603.

DOI: $10.1016 /$ j.compscitech.2003.11.009.

[41] Friebel, C., Doghri, I., Legat, V., (2006), General mean-field homogenization schemes for viscoelastic composites containing multiple phases of coated inclusions, International Journal of Solids and Structures, 43(9), pp. $2513-2541$. DOI: 10.1016/j.ijsolstr.2005.06.035.

[42] Daramola, O. O., Olajide, J. L., Adediran, A. A., Adewuyi, B. O., Ayodele, T. T., Sadiku, E. R., Desai, D. A., (2020), Multiscale analysis and experimental validation of the effective elastic modulus of epoxy-dioctahedral phyllosilicate clay composite, Heliyon 6, e04008, DOI:10.1016/j.heliyon.2020.e04008. 